Dear author,

In the stage of preparing your full work for evaluation, after receiving approval of the corresponding abstract, we kindly ask you to follow the next steps:

1. Update your approved abstract (you might want to introduce modifications) and submit it now in a written version according to the abstract template (many abstracts were introduced directly into the websystem). This version of the abstract will compose the abstracts booklet to be distributed to the participants when registering;

2. Fill the form in the next page, indicating to which section you would like your work to be directed. This will help organizing the sessions according to the mini-symposia advertised rather than in the areas and subareas present in the websystem. We apologize for this possible confusion. The reason is that we are using the websystem provided by ABCM, which does not allow us to introduce thematic sessions freely.

If any doubts arise, please contact us.

Your presence in MecSol 2017 will help making this a very successful event. We look forward to seeing you in Joinville!

With kind regards, 


\section{$6^{\text {th }}$ International Symposium on Solid Mechanics}

\section{Click on the box to select the Mini-Symposia:}

Multiaxial and Fretting Fatigue (Edgar Mamiya and Lucival Malcher);

$\bigotimes$ Composite Materials (Ricardo de Medeiros);

Constitutive Models I - Plasticity and Damage (Lucival Malcher, Miguel Vaz Jr. and Edgar Mamiya);

Constitutive Models II - Viscoelastic and Viscoplastic Solids: Models and Applications (Heraldo Mattos);

$\square$ Impact Engineering (Marcílio Alves);

Structural Reliability Methods and Reliability-Based Design Optimization (André Beck);

Topology Optimization of Multifunctional Materials, Fluids and Structures (Eduardo Lenz Cardoso e Emilio Carlos Nelli Silva);

$\square$ Topological Derivatives: Theory and Applications (André Novotny);

$\square$ X-FEM, G-FEM and Meshfree Methods (Roberto Dalledone Machado and Rodrigo Rossi);

High Order Finite Elements (Marco Lúcio Bittencourt);

$\bigotimes$ Nonlinear Analyses (Eduardo Campello);

$\square$ Other section; 


\title{
ANALISYS OF SANDWICH BEAMS USING TIMOSHENKO'S BEAM THEORY ASSISTED BY SOFTWARE
}

\author{
Douglas Rodrigues \\ Postgraduate Program in Mining, Metallurgical and Materials Engineering \\ Federal University of Rio Grande do Sul \\ rodriguesdouglas@ufrgs.br \\ Jessica Rocha \\ Postgraduate Program in Mining, Metallurgical and Materials Engineering \\ Federal University of Rio Grande do Sul \\ jessica.rochha@gmail.com \\ Eduardo Menezes \\ Postgraduate Program in Mechanical Engineering \\ Federal University of Rio Grande do Sul \\ eduardo.menezes@ufrgs.br \\ Sandro Amico \\ Postgraduate Program in Mining, Metallurgical and Materials Engineering \\ Federal University of Rio Grande do Sul \\ amico@ufrgs.br \\ *Corresponding author: rodriguesdouglas@ufrgs.br
}

\begin{abstract}
Sandwich structures are mainly used due to its low weight and high strength supporting compressive and flexural strengths, also showing excellent thermal insulation characteristics. Nowadays, sandwich beams are requested in many applications like aviation, missiles, boats and civil construction which demands an analytical method to predict its properties. It consists in a core rounded by a lamina or a laminate in both of your sides. Core's main function is to guarantee a high moment of inertia. The kinematic behavior of sandwich structures has been described based on formulations of laminated plate theories. This paper brings an analytical model for sandwich beams assisted by software, computed through Python algorithms. The software uses a database with properties and other pertinent information that serve as the basis for calculations. The user interface is user-friendly and allows calculations to be done more quickly and improves your experience. The analysis are based on classical laminate theory and Timoshenko plain beams deflection, since it attempts for the transversal shear displacement. As inputs, the program needs to be entered the core and laminate types, provided in its database, dimensions like height, breadth and length. As outputs, user obtains flexural rigidity of sandwich beam, core and face stresses, shear stresses, deflection and mass.
\end{abstract}

Keywords: Sandwich laminates, Timoshenko beam theory, software. 


\section{INTRODUCTION}

Sandwich structures are mainly used due to its low weight and high strength supporting compressive and flexural strengths, also showing excellent thermal insulation characteristics. Nowadays, sandwich beams are requested in many applications like aviation, missiles, boats and civil construction which demands an analytical method to predict its properties. It consists in a core rounded by a lamina or a laminate in both of your sides. Core's main function is to guarantee a high moment of inertia. The kinematic behavior of sandwich structures has been described based on formulations of laminated plate theories.

Constructive systems that uses panels sandwich provides good thermal and acoustic resistance and insulation. It may be an advantageous alternative to other types of construction, such as using masonry walls or pre-made of concrete.

The challenges derived from new materials, new processes and new structural concepts are inherent to the use of composites for flight vehicles due to needs of explicit safety requirements for development of the processes of design, manufacturing, maintenance, operation and requirements are tightly linked to change and innovation.

Looking for safety and integrity of these applications, the process must handle with the identification of minimal knowledge required to establish basic design data and knowledge bases and the costs that represent an important parcel of designs.

In general, composites are strongly used in applications due to its relation with sustainability thinking. A car built with polymer reinforced by natural fiber, for example, can use less oil due its low weight.

\section{COSTS IMPACT}

Cost is considered one of the most important aspect when the matter is structural composites and there are several issues that affects them. The emphasis is placed over recurring and nonrecurring costs, where recurring is the variable costs due to a part or piece produced and the nonrecurring cost is the cost incurred once during the fabrication run.

The recurring costs are related to raw materials, labor hours and cost of attaching parts to entire structure. There is no free software that provides an analytical model to predict final geometry, weight and estipulate properties.

According to [1]:

"The purpose of a "theoretical' cost model is the same as any theoretical model: to identify basic laws and apply them with the appropriate level of rigor (or simplification) in order to obtain useful estimates of system behavior."

Otherwise, a theoretical model can be created to estimate the properties and for the analysis of composite structures.

Non-recurring costs follows the phases of the project: Design phase, which the geometry is created and the fabrication process is selected; Analysis phase, where is determined the applied loads and the failure modes; Tooling, that englobe assembly jigs and fixtures; Testing, including the fabrication of specimens and testing of it and certification that is the most expensive, according to [2]. 
This scenario illustrates the needs to an analysis software that improves experience and provides theoretical results more quickly.

\section{CLASSICAL BEAM THEORY}

In first time, for the analysis of a panel, it is necessary to decide whether it will be analyzed with the behavior of a beam or panel, if the panel to be analyzed is supported only by two opposing edges, according to [3], there is an approximate way to decide that if the panel will be analyzed like a beam or a panel, and it can be made according to the following relations.

$$
\begin{gathered}
\frac{b}{a} \lesssim 0,3 \quad \text { (Beam Behavior) } \\
\frac{b}{a} \gtrsim 0,8 \quad \text { (Infinite panel under cilindric flexion) }
\end{gathered}
$$

Being $b$ the width and a the length of the panel. If the panel is supported by more than two edges, it must be analyzed as a panel.

\subsection{Model for a Simply Supported Beam}

To exemplify the calculation routine, a simply supported beam (Figure 1) will be used, where (1) represents the beam length, and (F) represents the applied load. The following is a sequence of formulas used as basis for the development of the sandwich design, about a simply supported beam, available in [3]. These formulas, are being obtained by the Euler-Bernoulli theory, and the Timoshenko theory. Bellow, the following beams which were considered to the calculations of software in Figures 1 to 6.

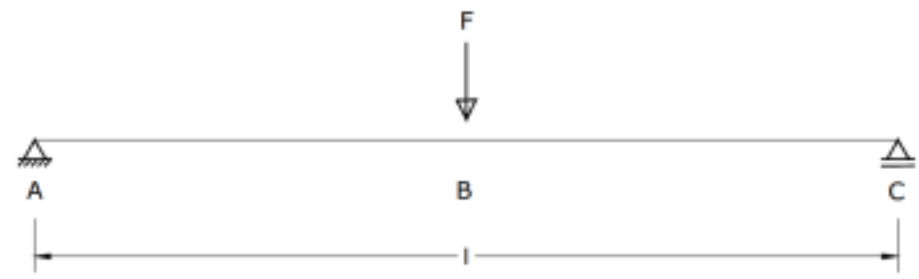

Figure 1 - Simple-Simple / Point beam

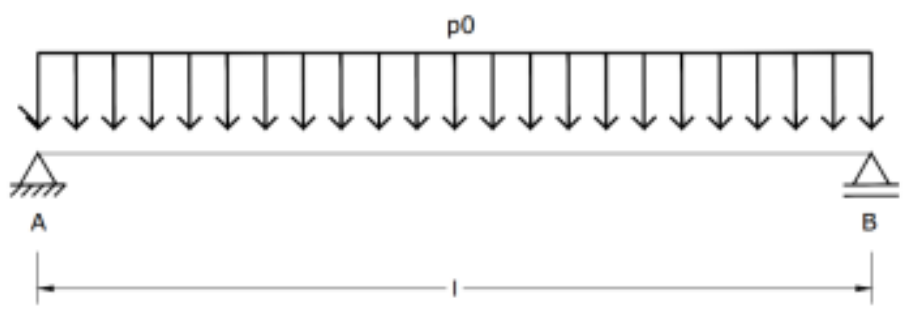

Figure 2 - Simple-Simple / Uniform beam 


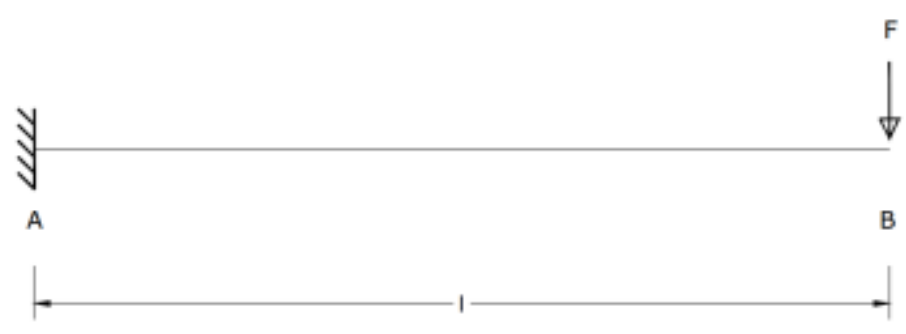

Figure 3 - Free-Fixed / Point beam

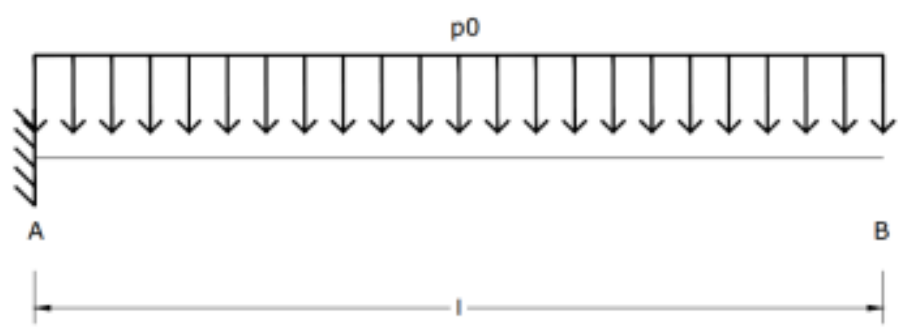

Figure 4 - Free-Fixed / Uniform beam

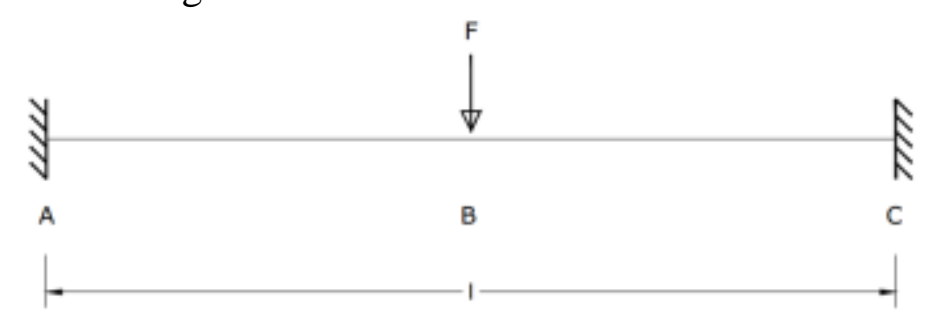

Figure 5 - Fixed-Fixed / Point beam

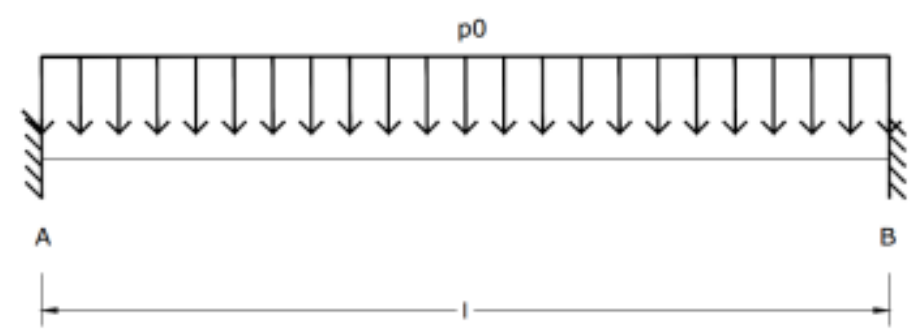

Figure 6 - Fixed-Fixed / Uniform beam

\section{SANDWICH BEAM PROJECT}

The Figure 7, represents the transversal beam section, where $t_{1}$ represents the thickness of the top face $1, t_{2}$ represents the thickness of the face $2, H_{n}$ represents the core height and $H_{m}$ represents the distance between the medial surfaces of the faces. 


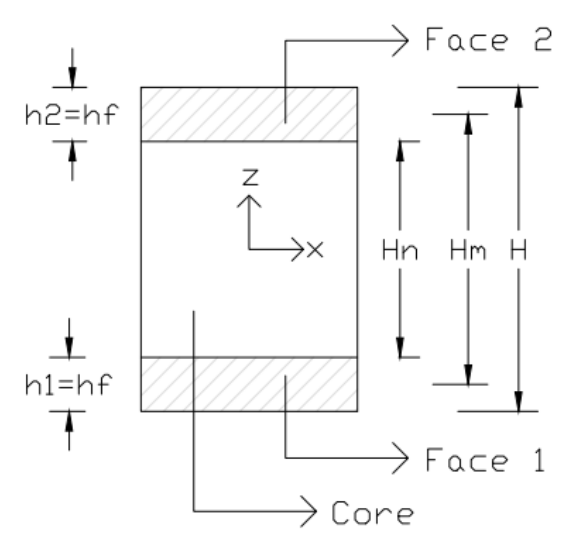

Figure 7 - Sandwich beam transversal section

\subsection{Sandwich beam bending}

Second [5-6], in a first moment, the behavior of a sandwich beam can be analyzed according to the use of the classical beam theories, as long as being considered the different proprieties of the involved materials, and the transverse shear effect in the displacements. Therefore, it is necessary to use Timoshenko's theory or a higher order in the transverse shear. All the calculations bellow in this sections are according to [3].

\subsection{Flexural stiffness of sandwich beam}

For a beam with equal faces and isotropic core, the flexural stiffness $\left(D_{v}\right)$, is obtained though the sum of the flexural stiffness of the faces, and the flexural stiffness of the core:

$$
\begin{gathered}
D_{v}=D_{\text {faces }}+D_{\text {core }} \\
D_{v}=E_{f} \frac{b h^{3}}{6}+E_{f} \frac{b h{H_{m}}^{2}}{2}+E_{n} \frac{b H_{n}{ }^{3}}{12}
\end{gathered}
$$

\subsection{Bending Solution for sandwiches beams}

The problem solution of bending in sandwiches beams can be equal to the applied in Timoshenko's beams, homogeneous and isotropic, it is only necessary that some substitutions be made. Solutions were obtained from the theory of Timoshenko, can be used in sandwich beams. 
According to [3], normal stresses occurs only in facings and the shear occurs in the core only, both are uniform in the core and across the thickiness of facings. Second [3], for a laminate $E_{f}=$ $E_{x N}$ which is the calculated as showed Table 1.

Table 1 - Young's Moduli for Lamina and Laminate

\begin{tabular}{|c|c|}
\hline$E_{f}($ Young's Modulus of the face $)=$ & For not aligned orthotropic lamina \\
$E_{x}($ Young's Modulus in the x direction $)$ & faces. \\
\hline$E_{f}($ Young's Modulus of the face $)=$ & For laminate faces. \\
$E_{x N}($ Young's Modulus related to the traction $)$ & \\
\hline
\end{tabular}

\subsection{Standard test method for sandwich structures}

Table 2 - Standard test methods used for calculations

\begin{tabular}{|c|c|}
\hline [7] ASTM C364/C364M-07 & $\begin{array}{c}\text { Standard test method for edgewise } \\
\text { compressive strength of sandwich } \\
\text { constructions. }\end{array}$ \\
\hline [8] ASTM C393-00 & $\begin{array}{c}\text { Standard test method for flexural } \\
\text { properties of sandwich constructions. }\end{array}$ \\
\hline [9] ASTM D3500-90(2004) & $\begin{array}{c}\text { Standard test methods for structural } \\
\text { panels in tension. }\end{array}$ \\
\hline [10] ASTM D 3501-05a & $\begin{array}{c}\text { Standard test methods for wood } \\
\text { based structural panels in compression. }\end{array}$ \\
\hline
\end{tabular}

\section{SANDWICH BEAMS ANALYSIS SOFTWARE}

Python was selected as programming language because its high performance and better application on scientific computing. The interface is simple and intuitive to promote an easy way to get the analytical properties.

As inputs, the program needs the Ex, Ey, vxy and Gxy, which are the engineering constants further the name of the laminate will be save this into program's database. To find this constants, were used the online software Mech-G because its quick response and theoretical base.

This software was made thinking in take less time of the researcher and provide a huge field of possibilities to improve your experience and provide more informations than other software commonly used in sandwich analysis.

In the Figure 2, first input data which are optional is showed and if "Save" button is pressed then the information goes to the system database. 


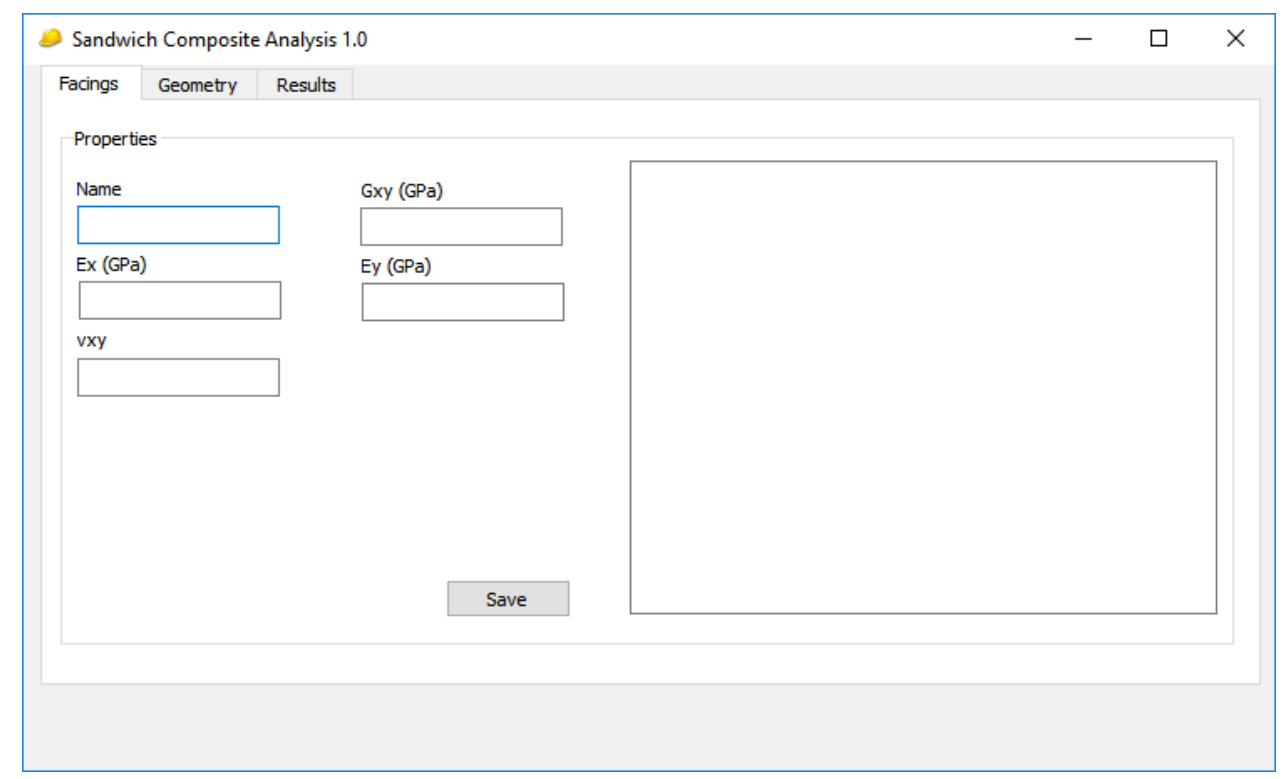

Figure 1 - Facings tab of Sandwich Composite Analysis software.

At the tab Geometry, the needs are to fill "load" field in Newtons and the dimensions of the beam. But before that, you need to select laminate, core type and beam type. For help visually when beam type is selected, the graphical representation of beam and load is showed on the right side of the current tab.

The program works with a native database that provide analysis data in seconds. But if you need to put your custom laminate, it is possible by entering engineering constants as inputs at the Facings tab, showed in the Figure 2.

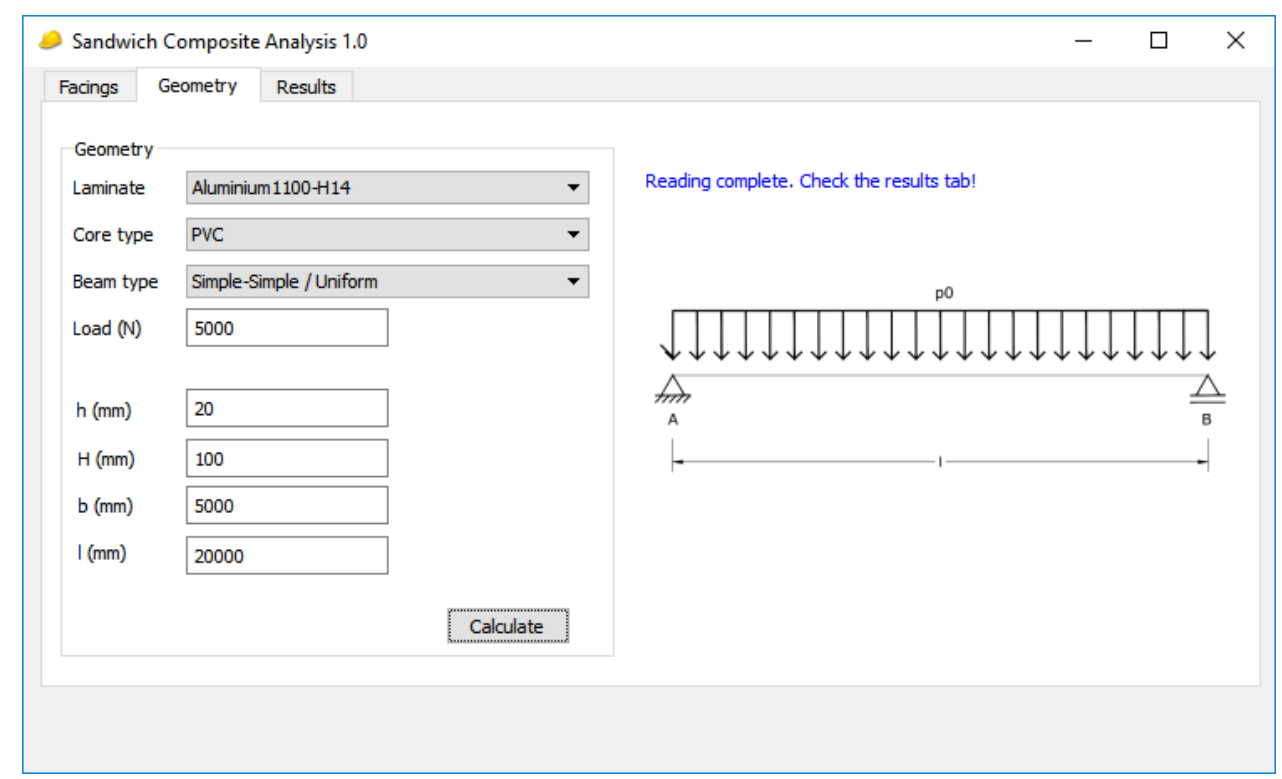

Figure 2 - Geometry tab of Sandwich Composite Analysis software. 


\section{RESULTS AND DISCUSSION}

In order to validate the software, experimental data reported by [6] were compared with the results obtained by Sancomp. The author performed a three-point bending test in sandwich beams composed by aluminium and foam core, measuring their transverse displacement. The material properties and beam geometry is reported in Table 3 .

Table 3 - Standard test methods used for calculations

\begin{tabular}{|l|l|}
\hline & Geometry \\
\hline Facing Thickness & $1 \mathrm{~mm}$ \\
\hline Core Thickness & $5 \mathrm{~mm}$ \\
\hline Width & $10 \mathrm{~mm}$ \\
\hline Span Lenght & $122 \mathrm{~mm}$ \\
\hline & Properties \\
\hline Young's Modulus for Aluminium & $70000 \mathrm{MPa}$ \\
\hline Young's Modulus for Foam & $26.08 \mathrm{MPa}$ \\
\hline Aluminium Poisson's ratio & 0.3 \\
\hline Foam Poisson's ratio & 0.284 \\
\hline Applied Force & $14.63 \mathrm{~N}$ \\
\hline
\end{tabular}

A moderate correlation was achieved between the vertical displacement measured by [6] and Sancomp. The experimental value was $0.498 \mathrm{~mm}$, while the value computed by Sancomp is 0.4297 $\mathrm{mm}$, yielding a difference of $13,71 \%$.

\section{CONCLUSION}

The program was able to make the calculations in seconds and improve the researcher experience. The results are satisfactory and match with examples encountered in literature. The Mech-G is confident and delivery information that is needed. Actually, there are feel options for analytical tools that can help researchers and engineers to estimate properties in many seconds, and it was what motivates a creation of this software.

\section{ACKNOWLEDGEMENTS}

The authors salutes Guido van Rossum by the creation of Python language, this marvelous programming tool.

\section{REFERENCES}

[1] T. Gutowski et al., "Development of a theoretical cost model for advanced composite fabrication," Compos. Manuf., vol. 5, no. 4, pp. 231-239, Dec. 1994. 
[2] R. Abbott, "Design and Certification of the All-Composite Airframe," 1989.

[3] P. de T. R. Mendonça, Materiais Compostos \&amp; Estruturas-Sanduíche, $1^{\mathrm{a}}$. Barueri - SP: Manole Ltda., 2015.

[4] D. P. Gagliardo and N. T. Mascia, "Análise de estruturas sanduíche: parâmetros de projeto," Ambient. Construído, vol. 10, no. 4, pp. 247-258, Dec. 2010.

[5] H. G. Allen, Analysis and design of structural sandwich panels, . Pergamon Press, 1969.

[6] A. Cernescu and J. Romanoff, "Bending deflection of sandwich beams considering local effect of concentrated force," Compos. Struct., vol. 134, pp. 169-175, Dec. 2015.

[7] AMERICAN SOCIETY FOR TESTING AND MATERIALS. ASTM Standard C364/C364M - 07: Standard test method for edgewise compressive strength of sandwich constructions. EUA: ASTM, 2007.

[8] AMERICAN SOCIETY FOR TESTING AND MATERIALS. ASTM Standard C393-00: Standard test method for flexural properties of sandwich constructions. EUA: ASTM, 2000.

[9] AMERICAN SOCIETY FOR TESTING AND MATERIALS. ASTM Standard D350090(2003): Standard test methods for structural panels in tension. EUA: ASTM, 2003.

[10] AMERICAN SOCIETY FOR TESTING AND MATERIALS. ASTM Standard D350105a:Standard test methods for wood based structural panels in compression. EUA: ASTM, 2005.

\section{RESPONSIBILITY NOTICE}

The authors are the only responsible for the printed material included in this paper. 